\title{
Development of autonomous navigation controller for agricultural vehicles
}

\author{
Xiang Yin ${ }^{1 *}$, Yanxin Wang ${ }^{1}$, Yulong Chen ${ }^{1}$, Chengqian $\mathrm{Jin}^{1,2}$, Juan $\mathrm{Du}^{1}$ \\ (1. School of Agricultural Engineering and Food Science, Shandong University of Technology, Zibo, Shandong 255000, China; \\ 2. Nanjing Research Institute for Agricultural Mechanization of Ministry of Agriculture and Rural Affairs, Nanjing 210014, China)
}

\begin{abstract}
Agricultural vehicles are adopted to undertake farming tasks by traversing along crop rows in the field. Working quality depends significantly on the driving skills of the operator. Automatic guidance has been introduced into agriculture to achieve high-accuracy path tracking during the last decades, which contributes considerably to straight-line navigation. The objective of this research was to develop an autonomous navigation controller that allowed movement autonomy for various agricultural vehicles. Three wheel-type vehicles were used as the test platform featuring automatic steering, hydrostatic transmission and speed control, which included a rice transplanter, a high-clearance sprayer and a tractor. A dual-antenna RTK-GNSS receiver was attached to the vehicles to provide spatial information on both positioning and heading by using the RTX service from Trimble. A path planning method was proposed to create a straight-line reference path by giving two points, and the target path was determined according to the vehicle initial status and working assignment. Headland turning was comprehensively taken into account by listing different turn patterns in order to realize autonomous navigation at the headland. The navigation controller hardware was fabricated for program execution, data processing and information communication with peripherals. A human-machine interface was designed for the operator to complete basic setting, path planning and navigation control by providing controls. Field experiments were conducted to evaluate the performance and versatility of the newly developed autonomous navigation controller in guiding agricultural vehicles to follow straight paths and turn at the headland. Results showed that an appropriate turn pattern was automatically executed when finishing straight-line navigation. The lateral error in straight-line tracking was no more than $6 \mathrm{~cm}, 6 \mathrm{~cm}$ and $5 \mathrm{~cm}$ for the rice transplanter, the high-clearance sprayer and the tractor, respectively. And the maximum lateral RMS error was $3.10 \mathrm{~cm}, 4.75 \mathrm{~cm}, 2.21 \mathrm{~cm}$ in terms of straight-line tracking, which indicated that the newly developed autonomous navigation controller was versatile and of high robustness in guiding various agricultural vehicles.
\end{abstract}

Keywords: autonomous navigation, navigation controller, agricultural vehicles, straight-line tracking, straight path, headland turning

DOI: $10.25165 /$ j.ijabe.20201304.5470

Citation: Yin X, Wang Y X, Chen Y L, Jin C Q, Du J. Development of autonomous navigation controller for agricultural vehicles. Int J Agric \& Biol Eng, 2020; 13(4): 70-76.

\section{Introduction}

Agricultural automation has been realized through the application of technologies in multiple disciplines including mechanics, electronics, computer science, automatic control, spectroscopy and so on, which makes a considerable contribution in saving labor force, alleviating driver fatigue, improving work efficiency and quality and increasing farmer profits ${ }^{[1-5]}$. Agricultural vehicles are widely utilized as important participants in soil-related field operations. Their automation level directly affects agricultural productivity. Consequently, many researchers concentrate their attention on automatic control and autonomous operation of agricultural vehicles, especially on precision localization and automatic guidance.

Spatial information needs to be known with respect to the local or global reference system to localize the agricultural vehicle and

Received date: $2019-10-20 \quad$ Accepted date: $2020-05-18$

Biographies: Yanxin Wang, Postgraduate, research interests: agricultural automation, Email: fywr2013@163.com; Yulong Chen, PhD, Lecturer, research interests: agricultural automation, Email: cyl06471@sdut.edu.cn; Chengqian Jin, $\mathrm{PhD}$, Professor, research interests: intelligent agricultural machinery, Email: 412114402@qq.com; Juan Du, PhD, Lecturer, research interests: agronomy for agricultural machinery, Email: dujuan0427@163.com

*Corresponding author: Xiang Yin, PhD, Associate Professor, research interests: agricultural automation and autonomy. Room 12-531, School of Agricultural Engineering and Food Science, Shandong University of Technology, Zibo 255000, China. Tel: +86-18369916558, Email: 666513@163.com. operating targets. For relative positioning in a local area, a variety of sensors were used to including laser range finder, computer vision and $3 \mathrm{D}$ camera ${ }^{[6-10]}$. For localization in the field, absolute positioning is preferred especially when there exist no reference objects. Therefore, global positioning sensors are used in automatic navigation of agricultural vehicles based on GNSS Positioning and heading compass technologies ${ }^{[11-14]}$.

On most occasions, agricultural vehicles are required to move in straight-line trajectories and cover operation all over the target field while the path planning pattern varies depending on different vehicles, implements and working requirements. Mogens and Plessen ${ }^{[15]}$ proposed two planning patterns to alleviate soil compaction by using a reduced weight control method and single-run field coverage. Jensen et al. ${ }^{[16]}$ presented a path planning method for transport units in agricultural operations involving in-field and inter-field transports for optimization criteria of time or traveled distance. Zhang et al. ${ }^{[17]}$ illustrated a path pattern to guide a crawler-type combine harvester to work from outside to inside by avoiding time consuming at the headland. Yin et al. ${ }^{[18]}$ showed autonomous navigation of a rice transplanter that was guided to travel parallel straight paths in order. And automatic guidance in most applications is intended to navigate agricultural vehicles to work in straight lines by considering convenience in the following management and harvesting ${ }^{[19-21]}$. Besides, headland turning contributes as an important consideration in farm work, which affects working efficiency to a great extent $^{[22-25]}$. Correspondingly, a variety of automatic navigation 
systems were developed by researchers and manufacturers to promote automation in agricultural production ${ }^{[26-28]}$. And more and more farmers come to adopt automatic guidance on their farms for a comfortable and profitable life.

The objective of this research was to develop an autonomous navigation controller for agricultural vehicles that were guided to follow straight paths and turn at headland according to the work assignment. A path planning method was proposed to create a straight path as the reference line by giving two points. During autonomous navigation, the target path was created according to the vehicle initial status, working parameters and work plan. Headland turning was comprehensively taken into account by listing different turn patterns in order to realize automatic moving control at the headland. The navigation controller hardware was fabricated for program execution, data processing and information communication with peripherals. A human-machine interface was designed for the operator to complete basic settings, path planning and navigation control by providing controls including texts and buttons.

\section{Material and methods}

A dual-antenna GNSS receiver was utilized to provide centimeter-level positioning information by using RTX service from Trimble as shown in Figure 1. Three test agricultural vehicles were used in this research, including a rice transplanter SPV-6C by Kubota Agricultural Machinery, a high-clearance sprayer by LOVOL ARBOS and a wheel-type tractor by ISEKI. Each of them featured a CAN-bus communication network for receiving operation commands from controllers and automatic mechanisms for automatic steering and speed control.

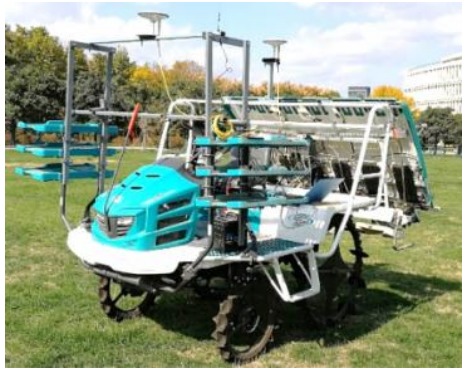

a. Rice transplanter

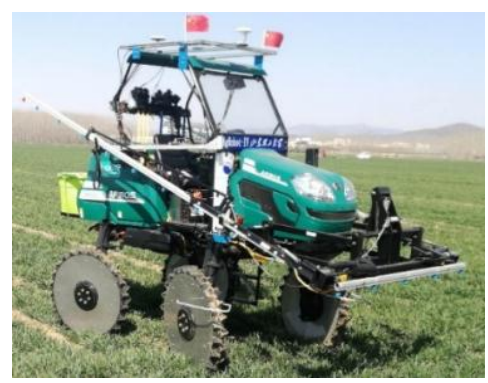

b. High-clearance sprayer

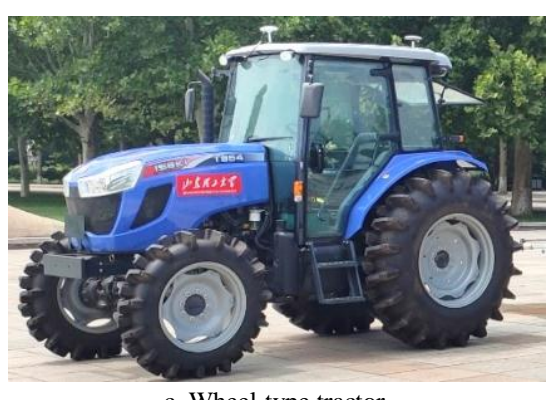

c. Wheel-type tractor.

Figure 1 Agricultural vehicle platforms in this research

\subsection{Path planning}

Agricultural vehicles move along predetermined paths to complete working tasks like tillage, spraying and harvesting under the structured environment of the field. In most cases, the operator drives into the target field and makes preparation with respect to actual conditions before starting work. Since it is a great challenge for the driver to find a reference on a large-scale farm, it is vital to take consideration of convenience in path planning and flexibility in path tracking.

In this research, we made a great effort in the management of straight paths. As shown in Figure 2, agricultural vehicles were desired to traverse the working area along straight paths parallel to each other. To simplify path planning, two points A and B were first measured and the straight line represented by $\mathrm{A}$ and $\mathrm{B}$ was taken as the reference path. Other paths were automatically generated during working by using the method introduced in the following.

Given the position of $\mathrm{A}$ and $\mathrm{B}$, the driver put the agricultural vehicle at an arbitrary location close to navigation paths, at $\mathrm{C}$ as an example. Since the vehicle is intended to move along straight paths parallel to line $\mathrm{AB}$ at a spacing of $n$ times of the working width, the current target path is determined by calculating $n$ according to Equation (1).

$$
\left.n=\left\lfloor\mid \frac{D}{W}\right\rfloor+0.5\right\rfloor
$$

In this way, the vehicle starts its movement along the closest path represented by $A_{n}\left(E_{A n}, N_{A n}\right)$ and $B_{n}\left(E_{B n}, N_{B n}\right)$, which are calculated according to Equations (2) and (3).

$$
\begin{gathered}
\left\{\begin{array}{l}
E_{A n}=E_{A}+\Delta E \\
N_{A n}=N_{A}+\Delta N
\end{array}\right. \\
\left\{\begin{array}{l}
E_{B n}=E_{B}+\Delta E \\
N_{B n}=N_{B}+\Delta N
\end{array}\right.
\end{gathered}
$$

where, $\Delta E$ and $\Delta N$ are differences between $\mathrm{A}$ and $A_{n}$ under the
UTM coordinate system.

The navigation path direction is another consideration in path planning since the vehicle direction relative to the target path constitutes one of the important parameters in tracking control. The navigation path direction is reversed if the angle between $\overrightarrow{A_{n} B_{n}}$ and $\boldsymbol{\Psi}$ is more than $90^{\circ}$. In this way, the autonomous navigation controller could understand the work assignment and intention of the operator.

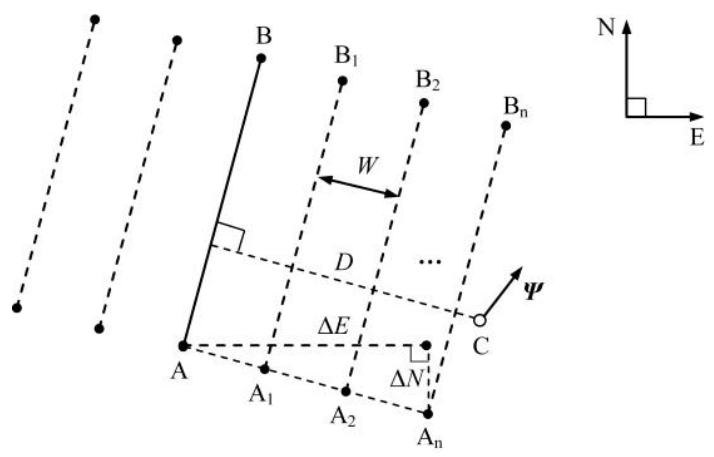

Figure 2 Path generation under the UTM coordinate system

\subsection{Headland turning}

For autonomous navigation of agricultural vehicles, turns at headland should be taken into comprehensive consideration besides straight-line tracking in most working tasks. An appropriate turn pattern helps considerably in reducing non-operating time and improving working efficiency. As depicted in Figure 3, three headland turn patterns were designed according to the relationship between the minimum turning radius $R$ and the working width $W$ of different implements.

The autonomous navigation controller would automatically select one from those patterns shown in Figure 3 when given the clearance turning radius $R$ and the working width $W$. And for precise control during the turning process, the actual value of $R$ is calculated and used by the autonomous navigation controller since 
slip exists between driving wheels and the ground and even for the

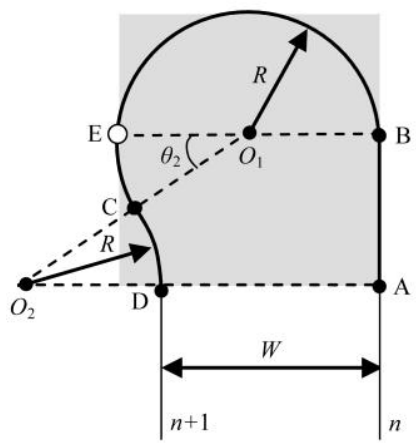

a.

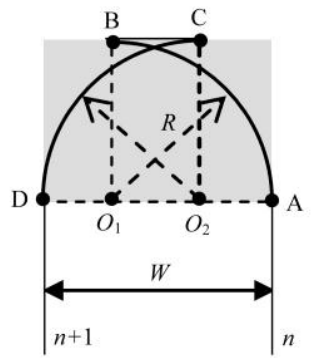

b.

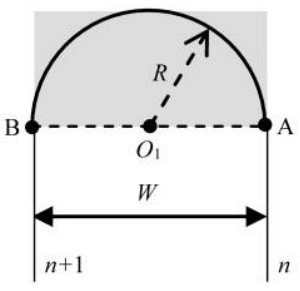

c.

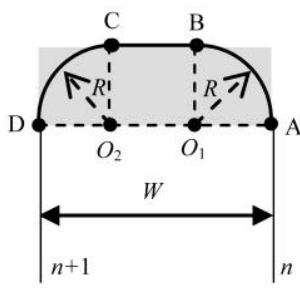

d.

Figure 3 Patterns for headland turning from path $n$ to path $n+1$ including (a) Keyhole: forward straight from A to B by a distance $\sqrt{4 R^{2}-W^{2}}$, turning left from B to $\mathrm{C}$ along the circle $O_{1}$, turning right from $\mathrm{C}$ to D along the circle $O_{2}$; (b) Switch-back: turning left from A to B by a quarter of the turning circle $O_{1}$, forward straight from B to $\mathrm{C}$ by a distance of $2 R-W$, turning left from $\mathrm{C}$ to $\mathrm{D}$ along the circle $O_{2}$; (c) Half-circle, turning left from A to B by a half turning circle $O_{1}$; (d) Square: turning left from A to B by a quarter of the turning circle $O_{1}$, forward straight to $\mathrm{C}$ by a distance of $W-2 R$ and then turning left to D by a quarter of the turning circle $\mathrm{O}_{2}$

\subsection{Navigation controller}

The autonomous navigation controller worked as the main component, which was used to process GNSS information, implement the navigation algorithm, manage the navigation information, and communicate with other devices. As shown in Figure 4, the navigation controller developed in this research was centered on a microcontroller by STMicroelectronics.

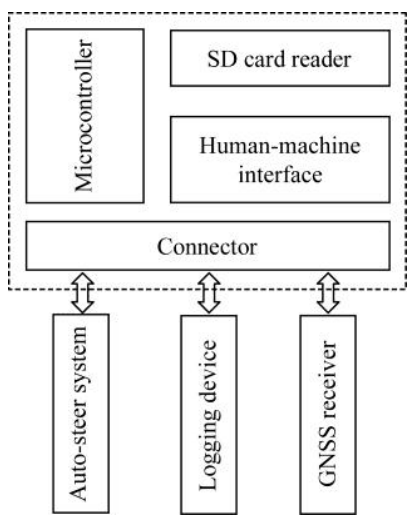

Figure 4 Navigation controller and its connections

The navigation controller is composed of an STM32F429 microcontroller, an SD card reader, a human-machine interface and a 23-pin connector with three serial interfaces for information communication with the GNSS receiver, the logging device and the automatic steering system, respectively. The SD card is a storage of files containing information about vehicle settings and navigation maps. The GNSS receiver sends positioning data by centimeter-level accuracy through the RS232 serial port. The human-machine interface contributes as an operation interface to be introduced in detail in section 2.4. Navigation information during automatic guidance is recorded by the logging device for post-analysis and system optimization. The automatic steering system receives and executes navigation commands to realize automatic control of speed and steer angle.

\subsection{Human-machine interface}

The human-machine interface (HMI) provides an interactive communication vehicle between the operator and the navigation controller, which displays the working status of the navigation controller in real-time during autonomous navigation and conveys human manipulation to the microcontroller. In this research, a 7-inch display with a touch screen was used as the HMI that communicated with the microcontroller through a serial port. Various controls were provided by the HMI provider for the developer in the realization of information communication, which included text, button, progress bar and so on. By considering the requirements of agricultural navigation, the graphical user interface was developed as shown in Figure 5.

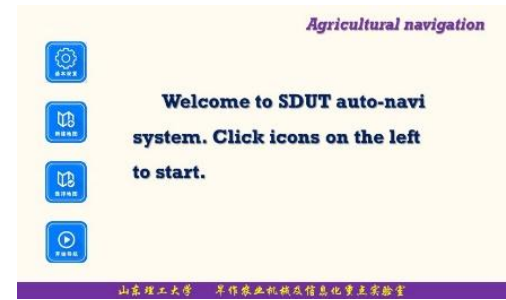

a. Initialization page

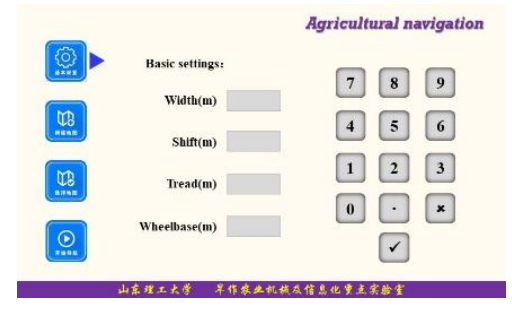

b. Functional pages for parameter setting

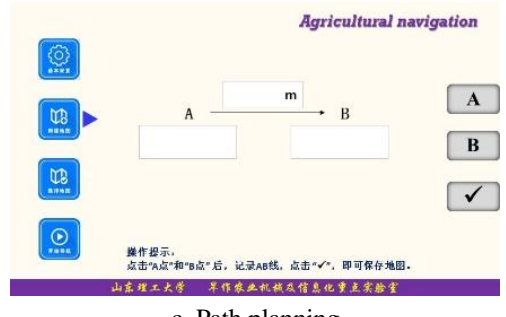

c. Path planning

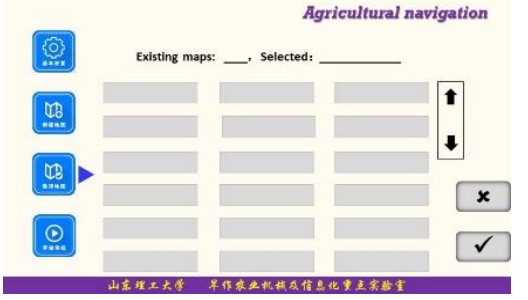

d. Map management

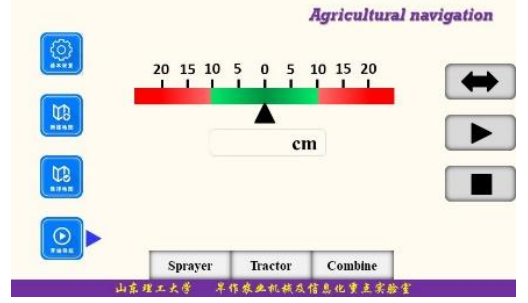

e. Navigation control

Figure 5 Graphical user interfaces 
Four buttons are assigned as the main menu on the left to switch between functional pages. Necessary controls were put on each function page for basic settings, creation of a new navigation map, management of navigation maps and status monitoring in navigation based on predetermined communication protocols between the microcontroller and the HMI.

\section{Results and discussion}

A series of field experiments were designed and conducted to evaluate methods proposed for path planning and headland turn, the stability and performance of the newly developed autonomous navigation controller by integrating it into those three typical agricultural vehicles. Operation tasks were assigned including rice transplanting, pesticide spraying and seeding to the rice transplanter, high-clearance sprayer, and wheel-type tractor, respectively.

\subsection{Navigation of the rice transplanter}

The target working area was roughly $35 \mathrm{~m}$ long and $20 \mathrm{~m}$ wide, according to which the straight-line navigation path was created by measuring the position of $\mathrm{A}_{1}(4074856.217,588247.395)$ and $\mathrm{B}_{1}$ (4074858.576, 588218.561) under the UTM coordinate system as shown in Figure 6. Parameters were given on the parameter setting page before starting automatic guidance with a clear turning radius and working width as $1.500 \mathrm{~m}$ and $1.8 \mathrm{~m}$, respectively. The working direction and headland turning patterns were configured as "from left to right" and "keyhole" on the navigation control page.
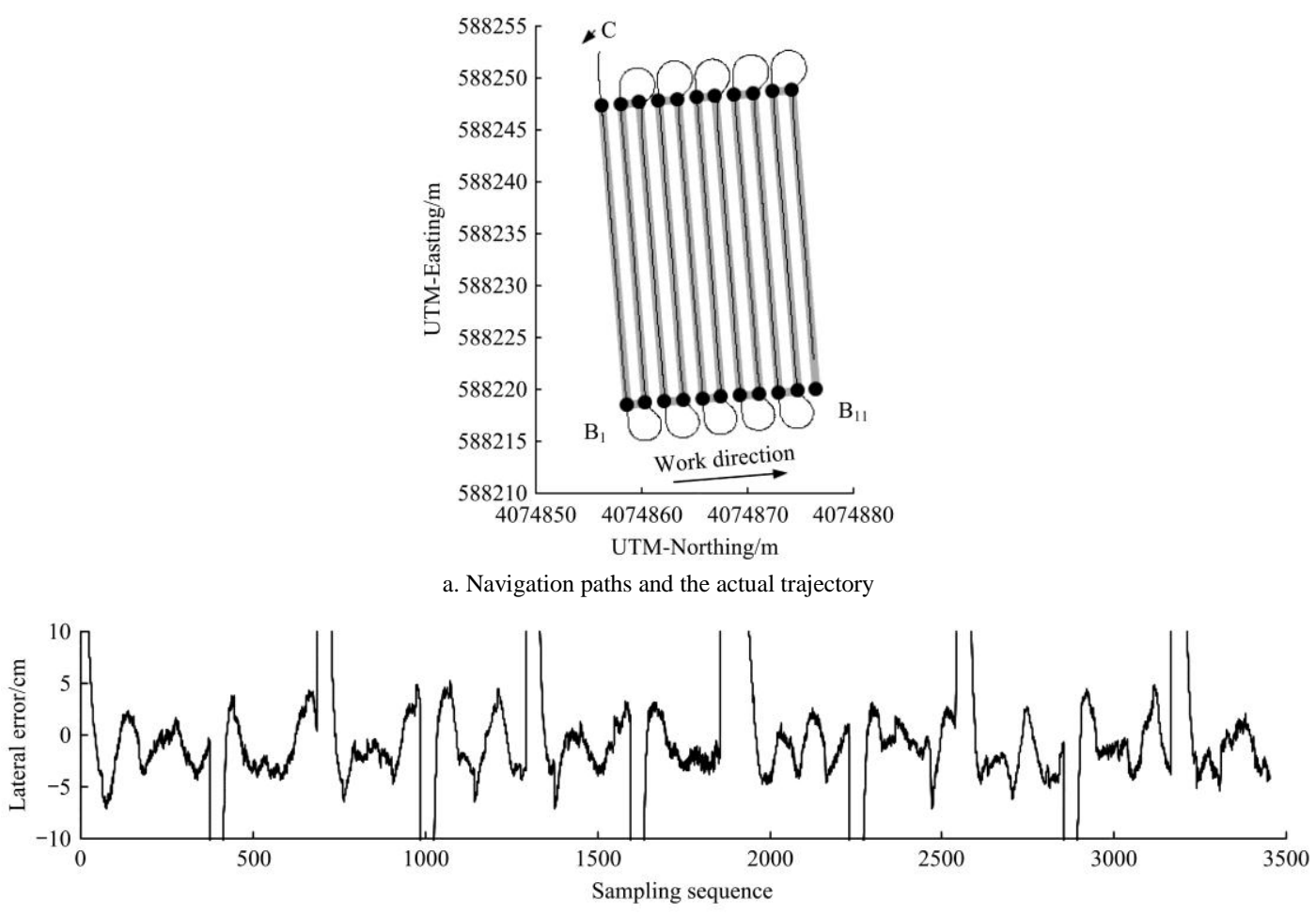

b. Lateral error

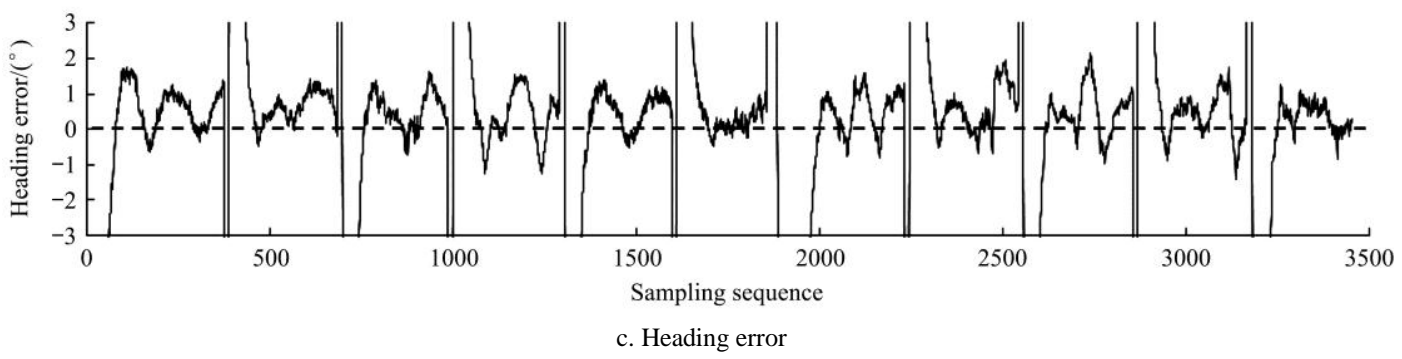

Figure 6 Autonomous navigation of rice transplanter

The rice transplanter was placed by the operator at $\mathrm{C}$ (4074855.995, 588252.626), heading roughly along from $A_{1}$ to $B_{1}$. The autonomous navigation controller calculated both lateral and heading errors as $206 \mathrm{~mm}$ and $4.68^{\circ}$, respectively. And the working intention was understood by the rice transplanter and it started transplanting from $A_{1}$ to $B_{1}$ and traversed 11 paths parallel to $A B$ from left to right by a spacing of $1800 \mathrm{~mm}$. Figures $6 \mathrm{~b}$ and $6 \mathrm{c}$ show lateral and heading errors during autonomous navigation. It was shown that the newly developed autonomous navigation controller could guide the rice transplanter along straight paths with lateral error and heading error no more than $5 \mathrm{~cm}$ and $2^{\circ}$, respectively. The lateral RMS error was $2.34 \mathrm{~cm}$, $2.40 \mathrm{~cm}, 2.88 \mathrm{~cm}, 3.24 \mathrm{~cm}, 2.11 \mathrm{~cm}, 2.32 \mathrm{~cm}, 2.76 \mathrm{~cm}, 2.35 \mathrm{~cm}$,
$3.10 \mathrm{~cm}, 3.06 \mathrm{~cm}$ and $2.71 \mathrm{~cm}$ for path 1, path 2, path 3, path 4, path 5 , path 6 , path 7 , path 8 , path 9 , path 10 and path 11 , respectively, when the agricultural vehicle movement converged to a steady-state after finishing headland turn. And the heading RMS error was $1.97^{\circ}, 1.25^{\circ}, 1.22^{\circ}, 2.01^{\circ}, 1.36^{\circ}, 1.41^{\circ}, 1.88^{\circ}$, $1.95^{\circ}, 1.62^{\circ}, 1.19^{\circ}$ and $1.28^{\circ}$ for path 1 , path 2 , path 3 , path 4 , path 5 , path 6 , path 7 , path 8 , path 9 , path 10 and path 11 , respectively. The turning pattern was exactly executed at the headland as depicted in Figure 6a. The actual turning radius value was calculated and updated for each turn by using positioning information since the slip rate varied from one area to another depending on soil conditions, which was $1.83 \mathrm{~m}, 1.83 \mathrm{~m}$, $1.83 \mathrm{~m}, 1.95 \mathrm{~m}, 1.83 \mathrm{~m}, 1.83 \mathrm{~m}, 1.76 \mathrm{~m}, 2.00 \mathrm{~m}, 1.83 \mathrm{~m}$ and 
$1.99 \mathrm{~m}$ for 10 turns at the headland, respectively. Those values were a little larger than that in the machine specifications since the GNSS positioning antenna was attached to the center of the front axle other than the vehicle geometrical center. Results showed that the rice transplanter autonomously worked in high accuracy and adequate stability in following straight paths and headland pattern throughout the target working area.

\subsection{Navigation of the high-clearance sprayer}

The high-clearance sprayer featured a three-section spraying boom of $10 \mathrm{~m}$ long and a clear turning radius of $3.0 \mathrm{~m}$. Specific parameters were input on the parameter setting page and the headland turn pattern was in "Square". The navigation path was defined by $\mathrm{A}_{1}$ (4073793.600, 588571.036) and $\mathrm{B}_{1}$ (4073796.08, 588551.188) as two end points as shown in Figure $7 \mathrm{a}$.

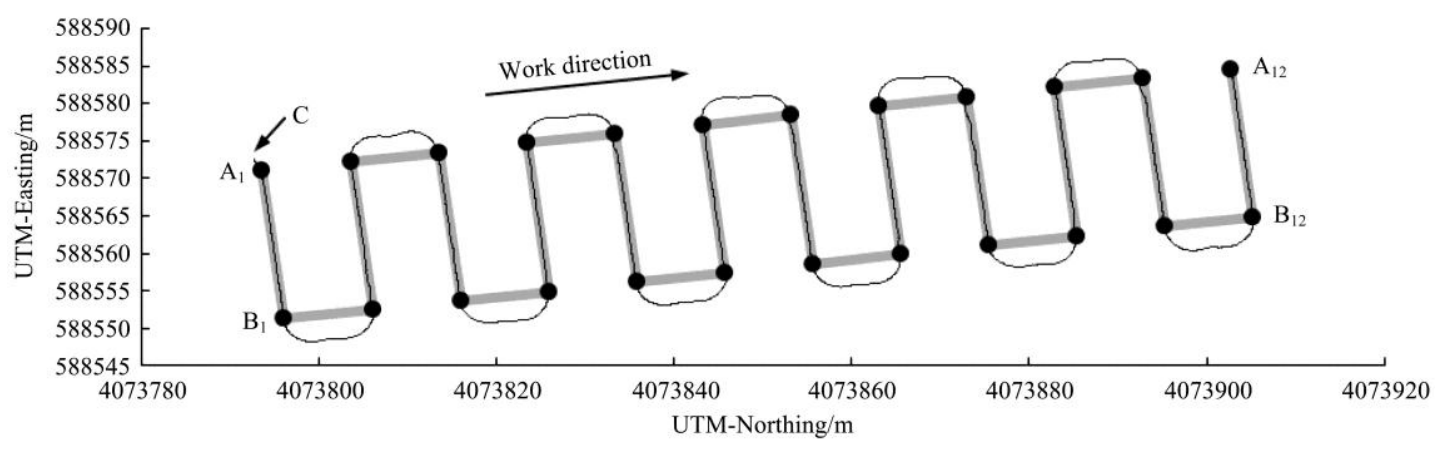

a. Navigation path in gray and thicker line and actual trajectory in black line
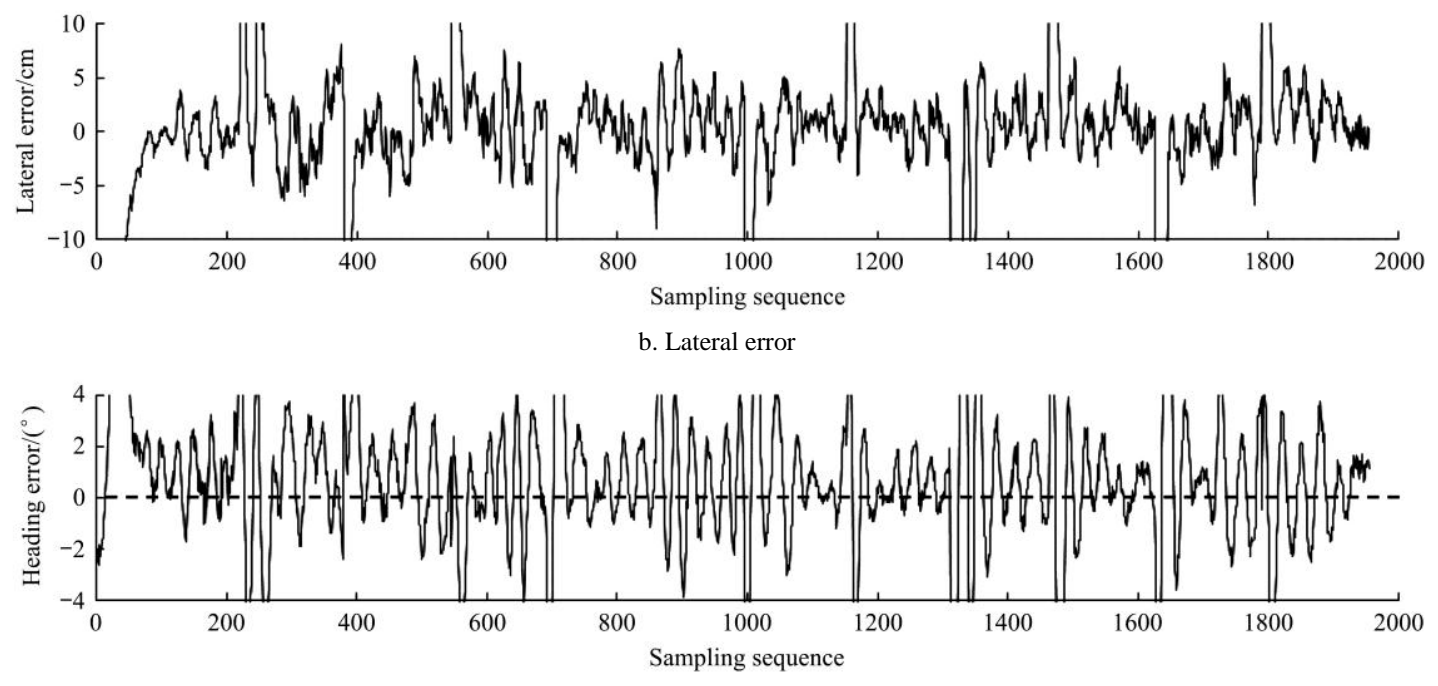

c. Heading error

Figure 7 Autonomous navigation of rice transplanter

The high-clearance sprayer started from C (4073792.692, 588572.591) and headed towards $B_{1}$ by an average speed of $4.0 \mathrm{~m} / \mathrm{s}$. Its movement experienced twelve straight paths and eleven headland turns in total. Figures $7 \mathrm{~b}$ and $7 \mathrm{c}$ show variation of lateral and heading errors during autonomous navigation in straight-line. Errors in lateral and heading were no more than $6 \mathrm{~cm}$ and $3^{\circ}$, respectively. The lateral RMS error was $1.84 \mathrm{~cm}$, $4.75 \mathrm{~cm}, 2.73 \mathrm{~cm}, 2.91 \mathrm{~cm}, 3.06 \mathrm{~cm}, 2.57 \mathrm{~cm}, 2.84 \mathrm{~cm}, 2.77 \mathrm{~cm}$, $3.11 \mathrm{~cm}, 3.20 \mathrm{~cm}, 1.98 \mathrm{~cm}$ and $2.45 \mathrm{~cm}$ for path 1, path 2, path 3, path 4 , path 5 , path 6 , path 7 , path 8 , path 9 , path 10 , path 11 and path 12 , respectively, when the movement trajectory came to be relatively stable after headland turn. And the heading RMS error was $1.10^{\circ}, 2.58^{\circ}, 1.90^{\circ}, 2.13^{\circ}, 2.23^{\circ}, 1.86^{\circ}, 2.11^{\circ}, 2.06^{\circ}$, $2.25^{\circ}, 2.23^{\circ}, 1.21^{\circ}$ and $1.74^{\circ}$ for path 1 , path 2 , path 3 , path 4 , path 5 , path 6 , path 7 , path 8 , path 9 , path 10 , path 11 and path 12 , respectively. For each headland turn, the actual turning radius was calculated according to positioning data in the first quarter circle, which was $3.32 \mathrm{~m}, 3.18 \mathrm{~m}, 3.46 \mathrm{~m}, 3.027 \mathrm{~m}, 3.34 \mathrm{~m}$, $3.05 \mathrm{~m}, 3.44 \mathrm{~m}, 3.12 \mathrm{~m}, 3.35 \mathrm{~m}, 3.03 \mathrm{~m}$ and $3.53 \mathrm{~m}$ for those turns in working order and the straight-line section during headland turning was determined. And the high-clearance sprayer was guided in the straight-line section in the same way the vehicle followed a straight path. It was indicated that the high-clearance sprayer was correctly and accurately navigated by the newly developed autonomous navigation controller in the completion of both straight path tracking and headland turning.

\subsection{Navigation of the wheel-type tractor}

Tractors are used to provide traction and power for various implements including seed drills, cultivators and plows. Its working width varies depending on different implements, which requires that the tractor be flexible in headland turning. In this research, the autonomous navigation controller could automatically select a turning pattern for the wheel-type tractor when values of the clear turning radius, the working width and headland space were given.

As shown in Figure 8a, the initial navigation path was straight from $\mathrm{A}_{1}(4074858.078,588215.539)$ to $\mathrm{B}_{1}$ (4074854.388, 588256.953). The tractor was arbitrarily placed at $\mathrm{C}$ (4074857.437, 588217.993) with the lateral and heading errors of $42 \mathrm{~cm}$ and $9^{\circ}$, respectively. Seven straight paths were covered and headland turn was in switch-back mode. The lateral RMS error was $1.55 \mathrm{~cm}, 1.96 \mathrm{~cm}, 1.84 \mathrm{~cm}, 1.86 \mathrm{~cm}, 2.21 \mathrm{~cm}, 1.62 \mathrm{~cm}$ and $1.82 \mathrm{~cm}$ for following those seven paths, respectively. And the maximum heading RMS error was $0.85^{\circ}, 1.41^{\circ}, 1.34^{\circ}, 1.36^{\circ}$, $1.42^{\circ}, 1.51^{\circ}$ and $1.50^{\circ}$. The maximum lateral error was less than 
$5 \mathrm{~cm}$ and the maximum heading error was no more than $2^{\circ}$ when the tractor converged into a steady state. Results presented accurate control in following and turning for the application of the autonomous navigation controller on the tractor.

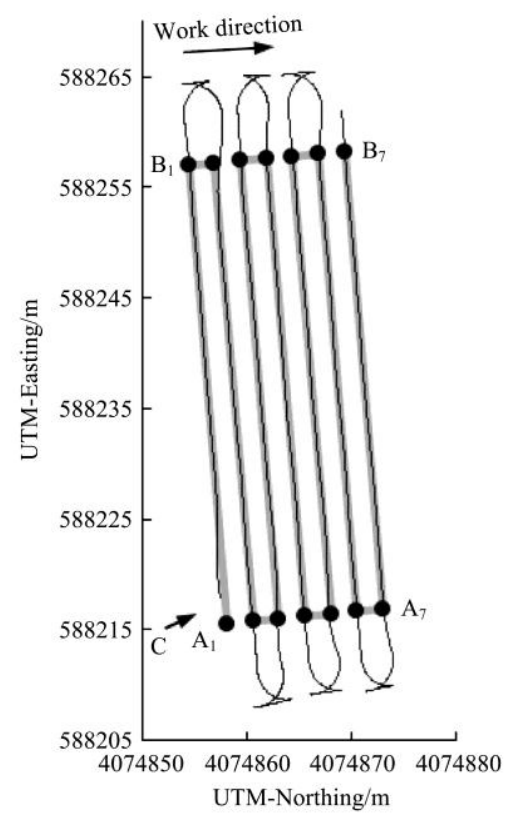

a. Navigation path and actual trajectory

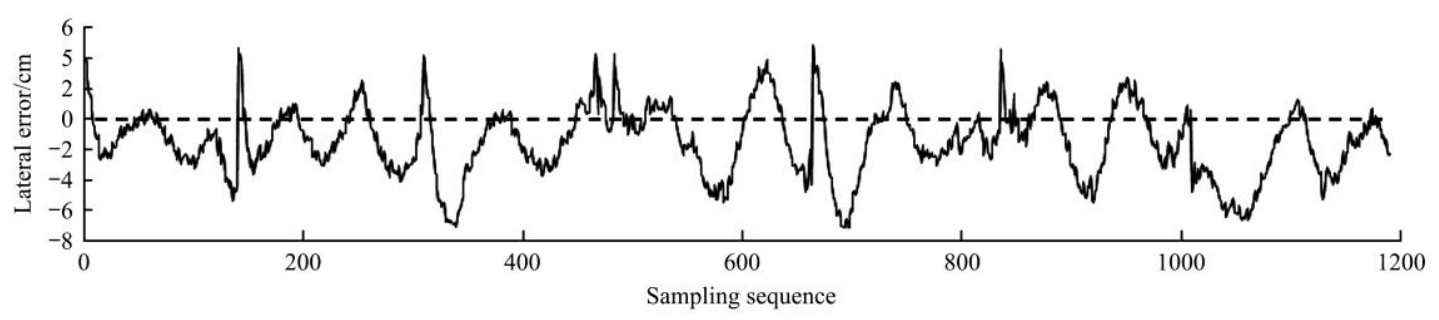

b. Lateral error

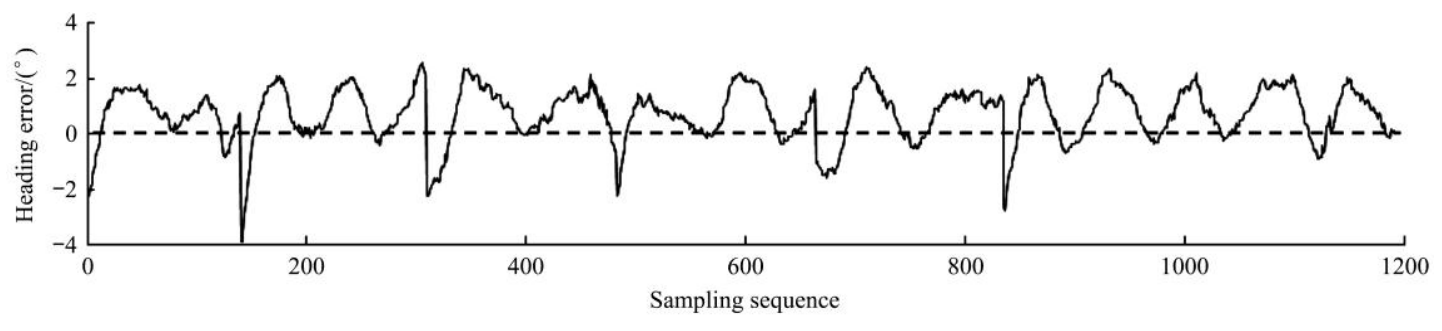

Figure 8 Autonomous navigation of wheel-type tractor

\section{Conclusions}

This research presented the feasibility of developing an autonomous navigation controller that could automatically guide agricultural vehicles to complete path following and headland turning. Three wheel-type vehicles were utilized as test platforms to evaluate the working performance of the navigation controller in terms of path planning, path following, headland turning, and applicability of both hardware and software. For improvement of operability in the field, a touch screen human-machine interface was designed for the operator to complete path planning and navigation control through various controls including texts and buttons.

Results in field tests showed that the maximum lateral error was no more than $6 \mathrm{~cm}, 6 \mathrm{~cm}$ and $5 \mathrm{~cm}$ for the rice transplanter, the high-clearance sprayer and the tractor, respectively. And the maximum lateral RMS error was $3.10 \mathrm{~cm}, 4.75 \mathrm{~cm}, 2.21 \mathrm{~cm}$ in terms of straight path tracking. It was indicated that the newly developed autonomous navigation controller was versatile for agricultural vehicles, based on which standardization of agricultural navigation could be drafted in terms of navigation accuracy, hardware and software of agricultural navigation systems in the future.

\section{Acknowledgements}

The authors acknowledge that this work was financially supported by National Key Research and Development Program of China Sub-project (2017YFD0700405); Key R\&D Project of Shandong Province (2019JZZY010734); National Natural Science Foundation of China (31501230); National Natural Science Foundation of China (51905318); and Shandong Province Science and Technology Planning Project of Higher Education (J17KA145).

\section{[References]}

[1] Raikwar S, Wani L J, Arun Kumar S, Sreenivasulu Rao M Hardware-in-the-loop test automation of embedded systems for agricultural tractors. Measurement, 2019; 133: 271-280. 
[2] Tröster M F, Pahl H, Sauer J. Effects of application costs on fertilizer application strategy. Computers and Electronics in Agriculture, 2019; 167(2019): 105033. doi: 10.1016/j.compag.2019.105033.

[3] Wang Y, Zhou J, Ji C, An Q. Design of agricultural wheeled mobile robot based on autonomous navigation and omnidirectional steering. Transactions of the CSAE, 2008; 24(7): 110-113. (in Chinese)

[4] Rahul K, Raheman H, Paradkar V. Design and development of a 5R 2DOF parallel robot arm for handling paper pot seedlings in a vegetable transplanter. Computers and Electronics in Agriculture, 2019; 166(2019): 105014. doi: 10.1016/j.compag.2019.105014

[5] Mohanraj I, Ashokumar K, Naren J. Field monitoring and automation using IOT in agriculture domain. Procedia Computer Science, 2016; 93(2016): 931-939.

[6] Thanpattranon P, Ahamed T, Takigawa T. Navigation of autonomous tractor for orchards and plantations using a laser range finder: Automatic control of trailer position with tractor. Biosystems Engineering, 2016; 147(2016): 90-103.

[7] Muñoz-Salinas R, Aguirre E, García-Silvente M. People detection and tracking using stereo vision and color. Image and Vision Computing, 2007; 25(6): 995-1007.

[8] Zhuang, Hou C, Tang Y, He Y, Luo S. Computer vision-based localisation of picking points for automatic litchi harvesting applications towards natural scenarios. Biosystems Engineering, 2019; 187(2019): $1-20$.

[9] Zhao T, Noguchi N, Yang L, Ishii K, Chen J. Development of uncut crop edge detection system based on laser rangefinder for combine harvesters. Int J Agric \& Biol Eng, 2016; 9(2): 21-28.

[10] Yin X, Noguchi N, Choi J. Development of a target recognition and following system for a field robot. Computers and Electronics in Agriculture, 2013; 98: 17-24.

[11] Yang L, Noguchi N, Takai R. Development and application of a wheel-type robot tractor. Engineering in Agriculture, Environment and Food, 2016; 9(2): 131-140.

[12] Tu X, Gai J, Tang L. Robust navigation control of a $4 \mathrm{WD} / 4 \mathrm{WS}$ agricultural robotic vehicle. Computers and Electronics in Agriculture, 2019; 164(2019): 104892. doi: 10.1016/j.compag.2019.104892.

[13] Jones M H, Bell J, Dredge D, Seabright M, Scarfe A, Duke M, et al. Design and testing of a heavy-duty platform for autonomous navigation in kiwifruit orchards. Biosystems Engineering, 2019; 187(2019): 129-146.

[14] Harper N, McKerrow P. Recognising plants with ultrasonic sensing for mobile robot navigation. Robotics and Autonomous Systems, 2001; 34(2-3): 71-82.
[15] Mogens M. Graf Plessen. Partial field coverage based on two path planning patterns. Biosystems Engineering, 2018; 171(2018): 16-29.

[16] Jensen M A F, Bochtis D, Sørensen C G, Blas M R, Lykkegaard K L. In-field and inter-field path planning for agricultural transport units. Computers \& Industrial Engineering, 2012; 63(4): 1054-1061.

[17] Zhang Z, Noguchi N, Ishii K, Yang L. Optimization of steering control parameters based on a combine harvester's kinematic model. Engineering in Agriculture, Environment and Food, 2014; 7(2): 91-96.

[18] Yin X, Du J, Noguchi N, Yang T, Jin C. Development of autonomous navigation system for rice transplanter. Int J Agric \& Biol Eng, 2018; 11(6): 89-94.

[19] Yao J, Teng G, Huo L, Yuan Y, Zhang F. Optimization of cooperative operation path for multiple combine harvesters without conflict. Transactions of the CSAE, 2019; 35(17): 12-18. (in Chinese)

[20] Wang H, Wang G, Luo X, Zhang Z, Gao Y, He J, Yue B. Path tracking control method of agricultural machine navigation based on aiming pursuit model. Transactions of the CSAE, 2019; 35(4): 11-19. (in Chinese)

[21] Yin X, Noboru N. Development and evaluation of a general-purpose electric off-road robot based on agricultural navigation. Int J Agric \& Biol Eng, 2014; 7(5): 14-21.

[22] Wei S, Li S, Zhang M, Ji Y, Xiang M, Li M. Automatic navigation path search and turning control of agricultural machinery based on GNSS Transactions of the CSAE, 2017; 33(Z1): 70-77. (in Chinese)

[23] Holpp M, Kroulik M, Kviz Z, Anken T, Sauter M, Hensel O. Large-scale field evaluation of driving performance and ergonomic effects of satellite-based guidance systems. Biosystems Engineering, 2013; 116(2013): $190-197$.

[24] Spekken M, Molin J P, Romanelli T L. Cost of boundary manoeuvres in sugarcane production. Biosystems Engineering, 2015; 129(2015): 112-126.

[25] Zhou K, Leck A J, Bochtis D D, Sørensen C G. Quantifying the benefits of alternative fieldwork patterns in a potato cultivation system. Computers and Electronics in Agriculture, 2015; 119 (2015): 228-240.

[26] Liu Z, Zhang Z, Luo X, Wang H, Huang P, Zhang J. Design of automatic navigation operation system for Lovol ZP9500 high clearance boom sprayer based on GNSS. Transactions of the CSAE, 2018; 34(1): 15-21. (in Chinese)

[27] Yang L, Wang Z, Luo J, Zhao Y, Li W, Bi B. Design and implementation of Xinjiang farmland navigation system based on android development. Transactions of the CSAM, 2019; 50(Supp): 57-61. (in Chinese)

[28] Li Y, Zhao Z, Huang P, Guan W, Wu X. Automatic navigation system of tractor based on DGPS and double closed-loop steering control. Transactions of the CSAM, 2017; 48(2): 11-19. (in Chinese) 